\title{
Chloride Ion
}

National Cancer Institute

\section{Source}

National Cancer Institute. Chloride Ion. NCI Thesaurus. Code C1741.

A chlorine anion that forms the negatively charged part of certain salts, including sodium and hydrogen chloride salts, and is an essential electrolyte located in all body fluids responsible for maintaining acid/base balance, transmitting nerve impulses and regulating fluid in and out of cells. 